\title{
Azotochelin and N-dihydroxy-N,N'- diisopropylhexanediamide as Fe sources to cucumber plants in hydroponic cultures
}

\author{
João Graça Martins' ${ }^{1}$, Clara Martin², Lourdes Hernandez-Apaolaza², Maria Teresa Barros ${ }^{3}$, \\ Helena Maria Vieira Monteiro Soares ${ }^{1 *}$, Juan José Lucena ${ }^{2 *}$ \\ ${ }^{1}$ REQUIMTE/LAQV- Department of Chemical Engineering, Faculty of Engineering, University of Porto, Porto, Portugal, ${ }^{2}$ Department of \\ Agricultural Chemistry, University Autónoma of Madrid, Madrid, Spain, ${ }^{3} R E Q U I M T E / L A Q V$, Department of Chemistry, Faculty of Science and \\ Technology, Universidade Nova de Lisboa, Caparica, Portugal
}

\section{A B S T R A C T}

\begin{abstract}
Environmental concerns related to the use of synthetic iron chelates, usually non-biodegradable, for overcoming iron chlorosis motivates the search for alternative compounds. Thus, the main aim of this work was to evaluate siderophore, azotochelin, and a siderophore mimic, $\mathrm{N}$-dihydroxy-N, $\mathrm{N}^{\prime}$-diisopropylhexanediamide (DPH) as potential sources of iron to cucumber plants grown in hydroponic cultures. The behavior of the iron chelates of azotochelin and DPH, as a substrate of ferric chelate reductase (FCR) and the ability as iron suppliers for chlorotic plants was studied and compared with $0,0-\mathrm{EDDHA} / \mathrm{Fe}^{3+}$ and EDTA/Fe ${ }^{3+}$ chelates, traditionally used for this purpose. The rate of reduction of $\mathrm{DPH} / \mathrm{Fe}^{3+}$, by $\mathrm{FCR}$, was comparable to $o, o-\mathrm{EDDHA} / \mathrm{Fe}^{3+}$ but lesser than the obtained for $\mathrm{EDTA} / \mathrm{Fe}^{+3}$. The rate of reduction for azotochelin $/ \mathrm{Fe}^{3+}$ was not possible to determine. Both azotochelin $/ \mathrm{Fe}^{3+}$ and $\mathrm{DPH} / \mathrm{Fe}^{3+}$ chelates were effective in supplying iron to cucumber plants. After 7 and 21 days, all the plants treated with the iron chelates (10 $\mu \mathrm{M}, \mathrm{Fe})$ of DPH and azotochelin showed significantly higher SPAD index, leaf dry weight and leaf Fe concentration than the control plants $(2 \mu \mathrm{M}, \mathrm{Fe})$. In conclusion, azotochelin/Fe ${ }^{3+}$ and $\mathrm{DPH} / \mathrm{Fe}^{3+}$ can be considered as iron sources for cucumber plants when growing in hydroponic culture.
\end{abstract}

Keywords: Iron chlorosis; Ferric chelate reductase; Siderophore; Hydroponic culture

\section{INTRODUCTION}

Iron chlorosis is a common and complex nutritional disorder that affects plant growth with insufficient quantities of available iron, especially in calcareous soils where calcium carbonate buffers soil solution at $\mathrm{pH} 7.5$ 8.5 and the concentration of bicarbonate is high. It is characterized by leaf yellowing that affects the development and decreases the yield of many crops (Villen et al., 2007; Rodriguez-Lucena et al., 2010b, 2011; Maqueda et al., 2011; Nadal et al., 2012).

Higher plants have developed efficient mechanisms for acquiring $\mathrm{Fe}$ in response to $\mathrm{Fe}$ deficiency, known as "Strategy I" and "Strategy II". Strategy I, found in dicotyledonous and non-graminaceous monocotyledonous, involves i) $\mathrm{Fe}(\mathrm{III})$ solubilization, usually by rhizosphere acidification, through proton extrusion, ii) the release of reductants and chelating compounds for Fe(III) complexation and mobilization and iii) the reduction of $\mathrm{Fe}(\mathrm{III})$ before iv) uptake into roots cell by a specific transporter for Fe(II) (Marschner and Romheld, 1994; Vansuyt et.al. 2007; Ma and Ling, 2009; Jin, et al., 2014). While Strategy I is characterized by soil acidification and Fe reduction for absorption of Fe(III), Strategy II plants secrete mugineic acid family phytosiderophores (MAs), synthesized by gramineous plants, to dissolve Fe in the rizosphere and acquire iron as Fe(III)-MAs complexes (Ding et al. 2009; Xiong et al. 2013).

Moreover, the direct uptake of Fe(III)-siderophore complexes without the requirement of a reduction step

\footnotetext{
${ }^{*}$ Corresponding author:

Helena Maria Vieira Monteiro Soares, REQUIMTE/LAQV, Department of Chemical Engineering, Faculty of Engineering, University of Porto, Rua Dr. Roberto Frias, 4200-465, Porto, Portugal. Phone:+351225081650; Fax: +351225081441.E-mail: hsoares@fe.up.pt Juan José Lucena, Department of Agricultural Chemistry, University Autónoma of Madrid, Avda. Francisco Tomás y Valiente, 7, 28049, Madrid, Spain. Phone: +34 91497 3968; Fax:+34 91497 3825. E-mail: juanjose.lucena@uam.es

Received: 26 June 2017; $\quad$ Accepted: 09 January 2018
} 
can also occur and the direct uptake of siderophores by strategy I plants was proposed by several authors. This ability was considered in the development of strategies to protect crops from Fe-limiting environments. Peanut/maize intercropping has shown to be a sustainable cropping system in farming practicy, which effectively improves Fe nutrition in peanuts, a strategy I plant species intercroped with maize, a strategy II plant species, in limed soils, when compared with peanut monoculture (Ding et al. 2009; Xiong et al. 2013). According to Ding et.al. (2009; 2010), this beneficial effect was associated with the increased siderophore secretion by maize and the increased Fe(III) reductase activity and transcript levels AhFRO1 by peanut. Xiong et al. reported that phytosiderophores released by Fe-deficient wheat promoted $\mathrm{Fe}$ acquisition and improved Fe nutrition in nearby peanuts, and the phytosiderophore deoxymugeinic acid (DMA) was detected in the roots of intercropped peanuts. Additionally the yellow stripe1-like (YSL) family of genes, which are homologous to maize yellow stripe 1 (ZmYS1), and that transport Fe(III)-MAs, where identified in peanut roots, suggesting that Fe(III)-DMA dissolved by maize might be absorbed directly by neibouring peanuts in peanut/maize intercropping system (Xiong et al. 2013).

Nowadays, the most efficient remedy to overcome and control iron chlorosis is the application of iron chelates to soils. However, most of these chelates are expensive and poorly biodegradable. After the chelate splitting (dechelation), these ligands lead to environmental concerns that arise from their persistence in the environment where they can solubilize heavy metals from soils and sediments and thus to increase the presence of metals in ground and drinking waters (Rodriguez-Lucena et.al. 2010a, b, 2011).

So, alternative compounds with Fe-complex forming comparable to the usual synthetic aminopolycarboxylates (APCAs) used and showing better biodegradability are needed to be introduced. Many siderophores [low molecular weight $(<1500 \mathrm{Da})$ chelating agents produced by a wide range of organisms (plant, fungal and bacterial) under iron limiting conditions (Crumbliss and Harrington, 2009)], namely those containing catechol and hydroxamic acid groups, evidence important characteristics (are Feeffective chelators, more selective to Fe(III) than to other divalent metals and better biodegradable than synthetic APCAs) that make them potentially substitutes of the synthetic APCAs, traditionally used for Fe fertilization.

The N,N'-dihydroxy-N,N'-diisopropylhexamide (DPH) (Fig. 1) is a biological and physicochemical model of the siderophore rhodotorulic acid, a dihydroxamic acid produced by Rhodotorula pilimane and related yeasts (Barclay et al., 1984). A recent study demonstrated the ability of $\mathrm{DPH}$ to maintain iron in a soluble form up to $\mathrm{pH} 9.5$ under

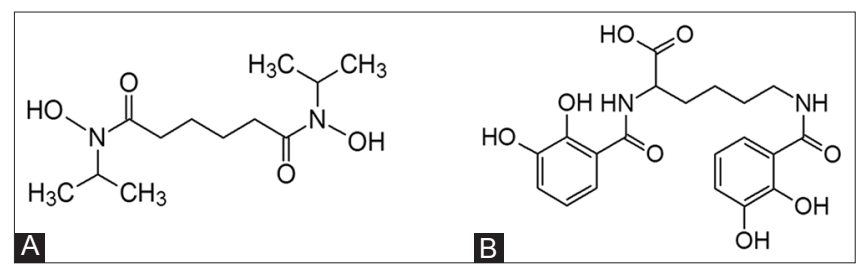

Fig 1. Structure of (A) N-Dihydroxy-N,N'-diisopropylhexanediamide $(\mathrm{DPH})$ and $(\mathrm{B})\left(\mathrm{N}, \mathrm{N}^{\prime}\right)$-2,6- Bis(2,3-dihydroxybenzoyl)-L-lysine] (azotochelin).

hydroponic conditions (Martins et.al. 2017). Moreover, the siderophore N,N'-2,6-bis(2,3-dihydroxybenzoyl)L-lisine, usually named as azotochelin, (Fig. 1) is a bis(catecholamide) siderophore produced by the nitrogenfixing soil bacterium Azotobacter vinelandii (Bellenger et al., 2007). The high efficiency of azotochelin, as iron chelator, has already been reported (Duhme et al., 1996, 1997; Cornish and Page, 1998). However, as far as we know, the ability of these two compounds for correcting iron deficiency of plants has never been evaluated. Based on these facts, the main purpose of this work was to evaluate the efficacy of the iron chelates of DPH and azotochelin to provide iron to cucumber (iron-efficient) plants in hydroponic cultures and to compare the results with those obtained with the iron chelates of o,o-ethylenediamineN,N'bis(o-hydroxy-phenylacetic) acid (o,o-EDDHA) and ethylenediaminetetraacetic acid (EDTA), commonly used in iron fertilization. Because the reduction of iron(III) to iron(II) is a mechanism widely described for iron uptake by dicotyledonous plants, the ability of iron chelates of azotochelin or iron chelates of DPH, to act as substrates in enzymatic reduction, by the ferric chelate reductase (FCR), at $\mathrm{pH} 7.5$, was also evaluated.

\section{MATERIALS AND METHODS}

All chemicals were of analytical grade. The chelating agents, o,o-EDDHA, 94,49\% (LGC Standards), $\mathrm{Na}_{2} \mathrm{H}_{2}$ EDTA 99\% (86\% as free acid) (Titriplex III, Merck), were purchased from the market. The titrimetric purity of o,o-EDDHA, expressed with respect to the acidic form, was determined as described in Yunta et al. (2003a).

\section{Synthesis of chelating agents}

All solvents used in the synthesis of $\left(N_{,}, N^{\prime}\right)-2,6-$ Bis(2,3-dihydroxybenzoyl)-L-lysine (azotochelin) and N-Dihydroxy-.N,N'-diisopropylhexanediamide (DPH) were purified by standard methods and distilled before use (Perrin et al., 1980). Elemental analyses were performed with a Thermo Finnigan-CE Flash EA 1112 CHNS series analyser. NMR spectra were recorded either on a Bruker AMX- $400 \mathrm{MHz}$ or a Bruker Avance- $600 \mathrm{MHz}$ apparatus, using as an internal standard, the residual peak of $\mathrm{H}_{2} \mathrm{O}$. 


\section{Synthesis of azotochelin}

Azotochelin was synthesized based on a literature procedure (Leydier et al., 2008) with an overall yield of 30\%, using 2,3-dihydroxybenzoic acid (1) and (S)ethyl 2,6-diaminohexanoate (4) (scheme A). ${ }^{1} \mathrm{H}$ NMR (DMSO-d $)_{6}: \delta 12.09$ (br s, 1H), 9.13 (br s), 8.88 (d, J = 7.4 $\mathrm{Hz}, 1 \mathrm{H}), 8.77$ (m, 1H), 7.45 (d, J = 7.8 Hz, 2H), 7.29 (d, $\mathrm{J}=7.9 \mathrm{~Hz}, 2 \mathrm{H}), 6.92-6.99(\mathrm{~m}, 2 \mathrm{H}), 6.67-6.72(\mathrm{~m}, 2 \mathrm{H})$, $4.44-4.48(\mathrm{~m}, 1 \mathrm{H}), 3.30-3.34(\mathrm{~m}, 2 \mathrm{H}), 1.67-1.72(\mathrm{~m}$, 2H), 1.35-1.58 (m, 4H). ${ }^{13} \mathrm{C}$ NMR: $\delta$ 173.7, 170.1, 169.9, 150.0, 149.5, 146.5, 129.2, 128.5, 119.1, 118.5, 118.2, 117.4, $115.5,115.3,52.7,39.1,30.6,28.7,23.6$ Anal. Calcd (\%) for $\mathrm{C}_{20} \mathrm{H}_{22} \mathrm{~N}_{2} \mathrm{O}_{8}$.THF: C, 58.89; H, 5.97; N, 5.72; O, 29.42. Found: C, 59.05; H, 6.22; N, 5.38.

\section{Synthesis of $D P H$}

DPH was synthesized according to scheme B, using the method described by Smith and Raymond (1980) as a white powder, with an overall yield of $60 \%$ as its hydrochloride salt. ${ }^{1} \mathrm{H}$ NMR (DMSO-d $): \delta 4.55(\mathrm{~m}, 2 \mathrm{H}), 2.32(\mathrm{t}, \mathrm{J}=6.4$ $\mathrm{Hz}, 4 \mathrm{H}), 1.48$ (t, J = 6.4 Hz, 4H), 1.04 (d, J = 6.6 Hz, 12 H). ${ }^{13} \mathrm{C}$ NMR: $\delta$ 177.2, 50.9, 36.9, 29.1, 24.2 Anal. Calcd (\%) for $\mathrm{C}_{12} \mathrm{H}_{26} \mathrm{Cl}_{2} \mathrm{~N}_{2} \mathrm{O}_{4}$ : C, 43.25; $\mathrm{H}, 7.86 ; \mathrm{N}, 8.41$. Found: C, 46.51: H, 7.94: N, 7.86.

\section{Preparation of the iron chelates}

For the preparation of the Fe chelate solutions, used in the hydroponic experiments, the amount of iron added was $5 \%$ in excess of the calculated requirements in order to<smiles>CCOC(=O)[C@H](N)CCCCNC(=O)[C@H](CCCCNC(=O)c1cccc(OCc2ccccc2)c1OCc1ccccc1)NC(=O)c1cccc(OCc2ccccc2)c1OCC</smiles>

a) $\mathrm{LiOH}, \mathrm{THF}$ $\mathrm{H}_{2} \mathrm{O}, \mathrm{rt}, 18 \mathrm{~h}$

b) $\mathrm{HCl}$<smiles>O=C(NCCCC[C@H](NC(=O)c1cccc(OCc2ccccc2)c1OCc1ccccc1)C(=O)O)c1cccc(OCc2ccccc2)c1OCc1ccccc1</smiles><smiles>O=C(NCCCC[C@H](NC(=O)c1cccc(O)c1O)C(=O)O)c1cccc(O)c1O</smiles><smiles>CCONC(=O)OCC(C)N(O)C(=O)CCCCC(=O)N(O)C(C)CC</smiles>

scheme 
ensure a complete metalation of the ligand. For reductase experiments, $5 \%$ excess of ligand was used to ensure total metal complexation. The $\mathrm{Fe}(\mathrm{NO})_{3}$ solution was added slowly to a solution of the ligand, previously dissolved in sufficient $\mathrm{NaOH}$. The formation of Fe:L complexes with stoichiometry of 3:2 was considered in the case of DPH (Barclay et al., 1984) and azotochelin (Cornish and Page, 1998) while the formation of 1:1 complexes was considered for EDTA and o,o-EDDHA.

During the chelation, the $\mathrm{pH}$ was maintained between 6.0 and 8.0. The $\mathrm{pH}$ was adjusted to 7.5 for azotochelin $/ \mathrm{Fe}^{3+}$ and $\mathrm{DPH} / \mathrm{Fe}^{3+}, 7.0$ for $0,0-\mathrm{EDDHA} / \mathrm{Fe}^{3+}$ and 6.5 for $\mathrm{EDTA} / \mathrm{Fe}^{3+}$. Solutions were left to stand overnight to allow the precipitation of Fe in excess as (hydr)oxides. In the case of azotochelin $/ \mathrm{Fe}^{3+}$ chelate, the solutions were stirred for $62 \mathrm{~h}$ and then left to stand overnight. Final solutions were filtered through a $0.45-\mu \mathrm{m}$ cellulose membrane (Milipore) and made up to volume to obtain the desired concentration with type I water (electrical conductivity max: $0.056 \mu \mathrm{S} \mathrm{cm}^{-1}$ at $25^{\circ} \mathrm{C}$; total organic $\mathrm{C}$ max: $100 \mu g \mathrm{~L}^{-1} ; \mathrm{Na}^{+}$max: $1 \mu \mathrm{g} \mathrm{L}^{-1}$; $\mathrm{Cl}^{-}$max: $1 \mu \mathrm{g} \mathrm{L}{ }^{-1}$; total Si max: $3 \mu \mathrm{g} \mathrm{L}^{-1}$ ). In order to prevent chelate photodecomposition, light exposure was avoided during preparation and storage of chelate solutions.

\section{Stability of the iron chelates of DPH and azotochelin} In order to compare the ligands effectiveness for iron chelation, theoretical computer calculations were performed to calculate the $\mathrm{pFe}$ values, at $\mathrm{pH} 7.5$, for the iron chelates of DPH, EDTA and o,o-EDDHA. The $\mathrm{pFe}$ values were determined based on chemical speciation calculations using the MINEQL+ Version 4.5 software (Schecher and McAvoy, 2001). Chemical equilibrium concentrations of all species considered in the model by the program reactions were generated based on the component stability constants and molar concentrations. Total ligand and iron concentrations of $10^{-5}$ and $10^{-6} \mathrm{M}$, respectively, which are usually described in the literature for this purpose (Zhang et al., 2009; Hider and Kong, 2010), were used together with the protonation and the stability constants between $\mathrm{Fe}^{3+}$ and DPH (Martell and Smith, 2004), o,o-EDDHA (Yunta et.al., 2003b) and EDTA (Martell and Smith, 2004). Precipitation of iron hydroxides was considered by introducing the solubility equilibrium for $\mathrm{Fe}(\mathrm{OH})_{3}(\mathrm{~s})(\log \beta=-2.94)$ (Martell and Smith, 2004).

The stability of the iron chelates of azotochelin or DPH in $\mathrm{CaCl}_{2}$ solutions $\left(\mathrm{Ca}^{2+}, 1.6 \times 10^{-3} \mathrm{M}\right)$ was determined at different $\mathrm{pH}$ values. An aliquot from the stock solution of the chelate prepared at $\mathrm{pH} 7.5$, as described in section 2.1 , using $5 \%$ excess of ligand was added to a solution of $\mathrm{CaCl}_{2}$. After adding a proper buffer (MES, HEPES or CAPSO, which do not complex iron (Ferreira et.al. 2015), the $\mathrm{pH}$ of each solution was adjusted to $\mathrm{pH}$ values between
4 and 11, with $\mathrm{HCl}$ or $\mathrm{NaOH}$ solutions, as needed; blanks were prepared at $\mathrm{pH}$ below 1 . Two replicates per $\mathrm{pH}$ were performed. The volume was then raised to $50 \mathrm{~mL}$ and the samples were shaken at $25^{\circ} \mathrm{C}$ and $56 \mathrm{rpm}$ for 3 days. At the end of each period, the $\mathrm{pH}$ of the solutions was measured using a Crison $5209 \mathrm{pH}$ combined electrode and a Crison MicropH 2002 meter. Additionally, the total soluble iron was determined by atomic absorption spectrometry with flame atomization (AAS-FA) using a Perkin-Elmer Analyst AA400 spectrophotometer after previous filtration of the samples with a $0.45 \mu \mathrm{m}$ Milipore membrane.

\section{Azotochelin/Fe ${ }^{3+}$ and DPH/Fe ${ }^{3+}$ as substrate for FCR activity in stressed cucumber plants}

Cucumber seeds (Cucumis sativus L. cv. Ashley) were germinated using a standard seed-growing procedure in sterilized trays (Garcia-Marco et al., 2006). The seeds were washed with water for $30 \mathrm{~min}$ and then placed in trays between two sheets of cellulose paper moistened with distilled water. The trays were kept in darkness at $28{ }^{\circ} \mathrm{C}$ for 4 days in a thermostated incubator.

After germination, seedlings were placed on a holed plate, floating in containers with a continuously aerated EDTA buffered (100 $\mu \mathrm{M}$ excess) nutrient solution with the following composition: macronutrients $(\mathrm{mM})-1.0$ $\mathrm{Ca}\left(\mathrm{NO}_{3}\right)_{2}, 0.9 \mathrm{KNO}_{3}, 0.3 \mathrm{MgSO}_{4}, 0.1 \mathrm{KH}_{2} \mathrm{PO}_{4}$; cationic micronutrients $(\mu \mathrm{M})-5.0 \mathrm{HBED} / \mathrm{Fe}^{3+}, 2.5 \mathrm{MnSO}_{4}, 1.0$ $\mathrm{CuSO}_{4}, 10 \mathrm{ZnSO}_{4}, 1.0 \mathrm{CoSO}_{4}, 1.0 \mathrm{NiCl}_{2}, 115.5 \mathrm{EDTANa}_{2}$; anionic micronutrients $(\mu \mathrm{M})-35 \mathrm{NaCl}, 10 \mathrm{H}_{3} \mathrm{BO}_{3}$, $0.05 \mathrm{Na}_{2} \mathrm{MoO}_{4}$; and $0.1 \mathrm{mM}$ HEPES, which is a noncomplexing compound (Ferreira et al. 2015), as pH buffer.

The $\mathrm{pH}$ of the solution was adjusted to 7.5 with $\mathrm{KOH} 1 \mathrm{M}$. Plants were grown in this nutrient solution for 6 days in a Dycometal-type CCKF 0/16985 growth chamber, where they were grown under controlled climatic conditions: day/night photoperiod, 16/8 h; temperature (day/night) $30 / 25 \circ$ C; relative humidity $(\mathrm{RH})$ (day/night) $50 / 70 \%$. The amount of Fe added $(5 \mu \mathrm{M})$ was found by Lucena and Chaney (2006) to be the most adequate to produce green but stressed cucumber plants.

Then, uniform seedlings, regarding the shoot growth, were selected and the stems of two individual plants were wrapped together with polyurethane foam and placed in a 12-L polypropylene bucket (12 pairs of plants per bucket) in a continuously aerated EDTA buffered nutrient solution, with the same composition as described above. The $\mathrm{pH}$ was buffered at 7.5 with HEPES $0,1 \mathrm{mM}$ and $2.4 \mathrm{~g} \mathrm{CaCO}_{3}$ per pot were added to simulate the conditions of calcareous soils. After 3 days, the plants were used for the reductase assay (RA). 
The FCR activity measurement was made in accordance with Lucena and Chaney (2006) at $\mathrm{pH}$ 7.5. The experiment was initiated within the following $2 \mathrm{~h}$ after the day-light period. A bunch of two plants was transplanted into $200 \mathrm{~mL}$ assay solution containing bathophenanthroline dissulfonic acid, disodium salt, $\left(\mathrm{Na}_{2} \mathrm{BDPS}, 300 \mu \mathrm{M}\right)$ and 5 $\mathrm{mL}$ of the corresponding treatment solution (o,oEDDHA/ $\mathrm{Fe}^{3+}, \mathrm{EDTA} / \mathrm{Fe}^{3+}$, azotochelin/ $\mathrm{Fe}^{3+}, \mathrm{DPH} / \mathrm{Fe}^{3+}$ ) was added (time 0 ) so that the final concentration of iron was $100 \mu \mathrm{M}$. For each treatment, six replicates were arranged. In addition, 2 blank replicates, per chelate, consisting of solutions without plants were included in order to correct reduction rates for slow photoreduction. Aliquots of 3 $\mathrm{mL}$ were sampled at $0,10,20,60$ and $120 \mathrm{~min}$ and the fresh weight of the roots was quantified at the end of the experiment.

The (BDPS) ${ }_{3} / \mathrm{Fe}^{2+}$ concentration was calculated as in Lucena and Chaney (2006) by determining the absorbance, using a JASCO V-650 UV-Vis spectrophotometer (JASCO Corporation, Tokyo, Japan), at $535 \mathrm{~nm}$ (maximum absorbance of the (BDPS) $3 / \mathrm{Fe}^{2+}$ complex) and at $480 \mathrm{~nm}$, $375 \mathrm{~nm}$ and $630 \mathrm{~nm}$ for the treatments with o,oEDDHA/ $\mathrm{Fe}^{3+}, \mathrm{DPH} / \mathrm{Fe}^{3+}$ and azotochelin $/ \mathrm{Fe}^{3+}$, respectively, to consider the contribution of the applied treatments on the total absorbance. With the exception of EDTA/ $\mathrm{Fe}^{3+}$ that did not present significant absorption at $535 \mathrm{~nm}$, the concentration of each chelate, was calculated by solving the two-equation system, exemplified below for the case of $\mathrm{o}, \mathrm{oEDDHA} / \mathrm{Fe}^{3+}$.

$$
\begin{aligned}
& A_{535}=a_{\mathrm{Fe} B D P S 535} \times\left[\mathrm{Fe}(\mathrm{BDPS})_{3}\right]+a_{0,0 \mathrm{EDDHA} / \mathrm{Fe} 535} \times \\
& {[0,0 \mathrm{EDDH} \mathrm{A} / \mathrm{Fe}]} \\
& A_{480}=a_{\mathrm{Fe} B D P S 480} \times\left[\mathrm{Fe}(\mathrm{BDPS})_{3}\right]+a_{0,0 \mathrm{EDDH} A / \mathrm{Fe} 480} \times \\
& {[0,0 \mathrm{EDDH} \mathrm{A} / \mathrm{Fe}]}
\end{aligned}
$$

where $A_{535}$ and $A_{480}$ are the absorbance measured for each sample at 535 and $480 \mathrm{~nm}$, respectively; $\alpha_{\text {FeBDPS535, }}$, $\alpha_{\mathrm{FeBDPS} 480}, \alpha_{\mathrm{o}, \mathrm{OEDDHA} / \mathrm{Fe} 535}$ and $\alpha_{\mathrm{o}, \mathrm{OEDDHA} / \mathrm{Fe} 480}$ are the molar absorption coefficients in the experimental conditions, and $\left[\mathrm{Fe}(\mathrm{BDPS})_{3}\right]$ and $[\mathrm{o}, \mathrm{oEDDHA} / \mathrm{Fe}]$ are the concentration of the chelates.

\section{Efficacy of azotochelin/ $/ \mathrm{Fe}^{3+}$ and DPH/Fe ${ }^{3+}$ to provide Fe to cucumber plants in hydroponic culture}

Cucumber seeds (Cucumis sativus L. cv. Ashley) were germinated using the same procedure as for reductase assays. After germination, seedlings of similar development (shoot growth) were placed on a holed plate, floating in containers with a continuously aerated nutrient solution with the same composition as in the
FCR assays, but $1 / 5$ diluted, for 6 days, in the growth chamber, where they were grown under controlled climatic conditions: day/night photoperiod, 16/8 h; temperature (day/night), $28 / 20{ }^{\circ} \mathrm{C}$; relative humidity (RH) (day/night) $40 / 60 \%$.

After this time, the stems of two plants were wrapped together with foam, and placed in $2 \mathrm{~L}$ polyethylene vessels [three holes in the lid, six plants (3 pairs) per pot] containing $2 \mathrm{~L}$ of a continuously aerated full strength nutrient solution with the same composition as in the reductase experiment. Iron was not added to this nutrient solution. The $\mathrm{pH}$ was adjusted to 7.5 with $\mathrm{KOH}$ $1.0 \mathrm{~mol} \mathrm{~L}^{-1}$ and buffered with HEPES $0.1 \mathrm{mM}$, and $0.4 \mathrm{~g}$ of solid $\mathrm{CaCO}_{3}$ per pot. The $2 \mathrm{~L}$ pots were covered with black plastic to avoid light exposure.

Plants were grown under these conditions until visual symptoms of iron deficiency were observed (6 days), when treatments were applied. The treatments with the iron $(10 \mu \mathrm{M})$ chelates of o,o-EDDHA, EDTA ${ }^{3+}, \mathrm{DPH}$ and azotochelin, respectively, as sources of iron were replicated five times in a completely randomized design, as well as the control containing $2 \mu \mathrm{M} \mathrm{HBED} / \mathrm{Fe}^{3+}$ (3 replicates). The growth chamber conditions were the same as those described above. Water was added every 2 days and the solution renewed weekly. During the experiment, SoilPlant Analysis Development (SPAD) index readings, with a chlorophyll-meter (Minolta SPAD-502) were taken for all the leaf stages (average of three readings per leaf) at several times.

Whole plants were sampled 7 (two pairs of plants) and 21 (one pair of plants) days after application of the treatments. After sampling, plant nutritional status and Fe redistribution were studied. The sampled roots, stems and leaves were separated, weighed and washed with a $0.01 \%$ non-ionic detergent (Tween 80 ) in $0.1 \% \mathrm{HCl}$ solution for 30 seconds and rinsed twice with ultrapure water following the procedure of Garcia-Marco et al. (2006). Then, samples were dried in a forced air oven at $65^{\circ} \mathrm{C}$ for 3 days. Fresh and dry (DW) weights were determined. After dry digestion in a muffle furnace (480 ${ }^{\circ} \mathrm{C}$ ), the ashes were dissolved in $6 \mathrm{M} \mathrm{HCl}$. Micronutrients were determined in stems and leaves. $\mathrm{Fe}, \mathrm{Mn}, \mathrm{Cu}$ were analysed by AAS-FA.

\section{Statistical analysis}

Statistical analyses were performed with SPSS statistical software (v.21; SPSS, Chicago, IL, USA). Differences among treatments were determined using a one-way analysis of variance (ANOVA). Significant differences were established at $\mathrm{p}<0.05$ using the Duncan test. 


\section{RESULTS}

Stability of the iron chelates of DPH and azotochelin The $\mathrm{pFe}^{3+}$ value express the amount of "free iron" present in equilibrium under particular set of conditions. Usually, calculated $\mathrm{pFe}^{3+}$ values, assuming total ligand and iron concentrations of $10^{-5}$ and $10^{-6} \mathrm{M}$, respectively, at $\mathrm{pH} 7.4$, are used for a direct comparison of the iron stability of the different chelates in solution (Zhang et al., 2009; Hider and Kong, 2010). Thus, assuming these conditions, computer chemical simulations were performed to calculate $\mathrm{pFe}^{3+}$ values at $\mathrm{pH}$ 7.5, for DPH, o,o-EDDHA, and EDTA in aqueous solution. The $\mathrm{pFe}$ value for azotochelin at $\mathrm{pH} 7.4$ (23.1) was reported by Cornish and Page, (1998). These results predict that the iron chelates of $0,0-$ EDDHA are the most stable at $\mathrm{pH} 7.5\left(\mathrm{pFe}^{3+}=27.2\right)$. The $\mathrm{pFe}$ value for azotochelin is slightly higher than for EDTA $\left(\mathrm{pFe}^{3+}=\right.$ 22.8) while $\mathrm{DPH} / \mathrm{Fe}^{3+}$ chelates are the less stable $\left(\mathrm{pFe}^{3+}=\right.$ 20.8) at $\mathrm{pH} 7.5$.

Figs. $2 \mathrm{~A}$ and $2 \mathrm{~B}$ show the percentage of $\mathrm{Fe}$ remaining in $\mathrm{DPH} / \mathrm{Fe}^{3+}$ and azotochelin/ $\mathrm{Fe}^{3+}$ solutions, respectively, at different $\mathrm{pH}$ after 3 days of interaction with $1.6 \mathrm{mM}$ of $\mathrm{CaCl}_{2}$. These results confirm the high stability of the iron chelates of azotochelin or DPH at $\mathrm{pH}$ 7.5. In the case of azotochelin, all Fe remained in solution between $\mathrm{pH} 6$ and 10 while in the case of DPH a slight decrease of soluble Fe was observed above $\mathrm{pH} 6.5$; nevertheless, $95 \%$ of the Fe remained in solution at $\mathrm{pH}$ 7.5.

\section{Azotochelin/ $/ \mathrm{Fe}^{3+}$ and $\mathrm{DPH} / \mathrm{Fe}^{3+}$ chelates as substrate for FCR activity in stressed cucumber plants}

The ability of the iron chelates of azotochelin, DPH, EDDHA and EDTA to act as substrates in enzymatic reduction was evaluated; Fe-stressed, but still green, cucumber plants were used in these experiments.

The Fe reduction rate $\left(\mu \mathrm{mol} \mathrm{Fe}(\mathrm{II}) \mathrm{g}^{-1}\right.$ fresh root $\mathrm{h}^{-1}$ ) using EDTA/ $\mathrm{Fe}^{3+}$, o, o-EDDHA/ $/ \mathrm{Fe}^{3+}$ and $\mathrm{DPH} / \mathrm{Fe}^{3+}$ chelates is shown in Fig. 3. For azotochelin $/ \mathrm{Fe}^{3+}$ chelate, the reduction rate was not possible to be determined due to the non-negligible changes observed in the blanks that lead to misleading results (data not shown).

The reduction assays were conducted for $2 \mathrm{~h}$. The reduction rate for EDTA/ $\mathrm{Fe}^{3+}$ chelate was significantly higher than for the other iron chelates; $\mathrm{DPH} / \mathrm{Fe}^{3+}$ chelate showed a similar activity to the observed for o,o-EDDHA/ $\mathrm{Fe}^{3+}$ chelate. A slight decrease in the levels of reductase activity for $\mathrm{DPH} / \mathrm{Fe}^{3+}$ was observed in the second hour.

Efficacy of azochelin/ $/ \mathrm{Fe}^{3+}$ and DPH/Fe ${ }^{3+}$ chelates to provide iron to cucumber plants in hydroponic culture In this experiment, four different $\mathrm{Fe}(10 \mu \mathrm{M})$ chelate treatments were applied to Fe- efficient cucumber plants with visible chlorotic symptoms. The effect of the iron chelates of azotochelin $/ \mathrm{Fe}^{3+}, \mathrm{DPH} / \mathrm{Fe}^{3+}, \mathrm{EDDHA} / \mathrm{Fe}^{3+}$ and EDTA/ $\mathrm{Fe}^{3+}$ was evaluated and the results were compared with the control (Fe limited: $2 \mu \mathrm{M} \mathrm{Fe}, \mathrm{HBED} / \mathrm{Fe}^{3+}$ ).

The SPAD index was measured in the following days after the application of the treatments (DAT) to estimate the chlorophyll concentration and recovery during the experiment. Fig. 4 shows the time course of the SPAD index, measured in the first leaf level (the first developed after the cotyledons).

After the application of the treatments, all four iron chelates showed significantly higher SPAD values than the control in all leaf levels and in all stages of the experiment. These results are in agreement with the visual symptoms of iron deficiency exhibited by the control plants during the experiment. In the leaves of the first level, a marked increase of the SPAD index was observed after the third day of treatment with all chelates (Fig. 4) while, in the control, only a slight increase of the SPAD index was observed after the day 7 .

Table 1 shows the SPAD index for the most recently developed leaves formed in different leaf levels after the

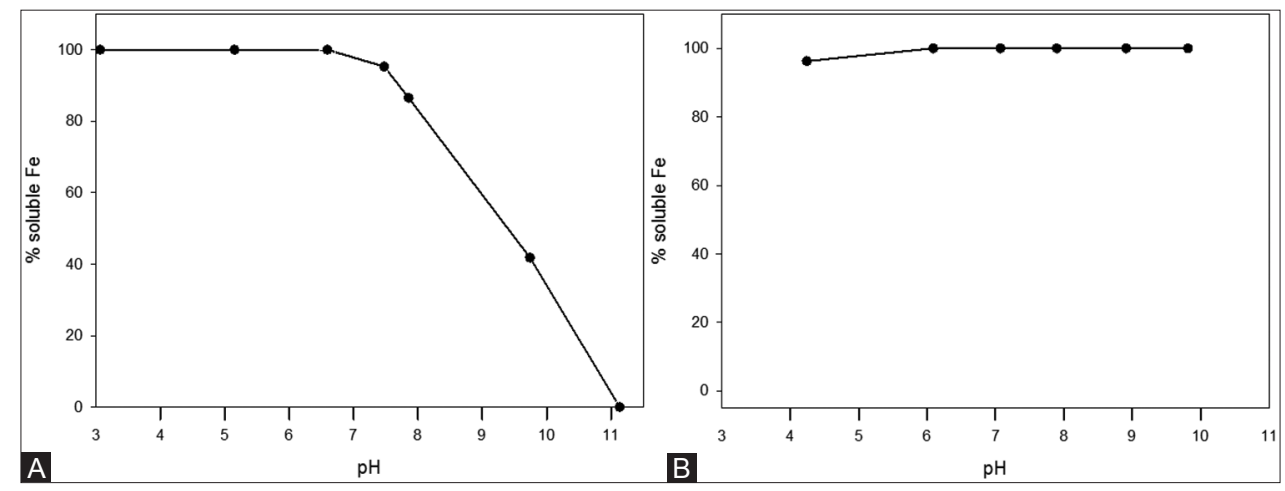

Fig 2. Effect of the $\mathrm{pH}$ on the percentage of soluble $\mathrm{Fe}$, after 3 days of interaction: $(\mathrm{A}) \mathrm{DPH} / \mathrm{Fe}^{3+}\left(1.0 \times 10^{-4} \mathrm{M} \mathrm{Fe}\right)$ and $(\mathrm{B})$ azotochelin/Fe $\mathrm{Fe}^{3+}$ $\left(1.5 \times 10^{-4} \mathrm{M} \mathrm{Fe}\right)$ in the presence of $\mathrm{Ca}^{2+} 1.6 \times 10^{-3} \mathrm{M}$. 
application of the treatments (3 DAT, second level; 7 DAT, third level; 14 DAT, fourth level and 21 DAT on second, third, fourth and fifth levels). At the end of the experiment (21 DAT), the SPAD measured in the upper leaf levels were similar in all the treated plants, with the exception of the fourth leaf level, where SPAD index in the leaves

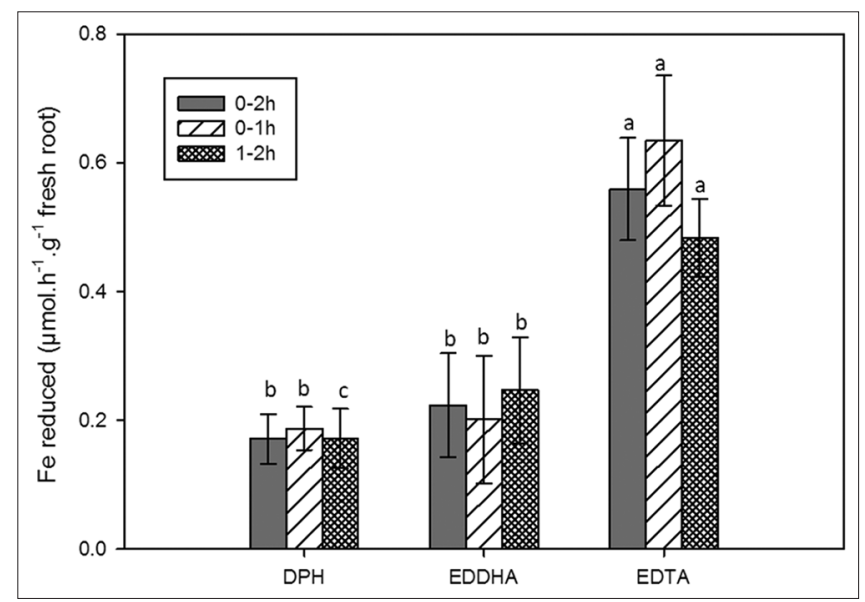

Fig 3. Rate of $\mathrm{Fe}^{3+}$ reduction of the iron chelates of DPH, EDDHA and EDTA, for cucumber plants. Error bars represent standard deviations $(S D, n=6)$. Different letters in the same period denotes significant differences among treatments for Duncan test $(p<0.05)$.

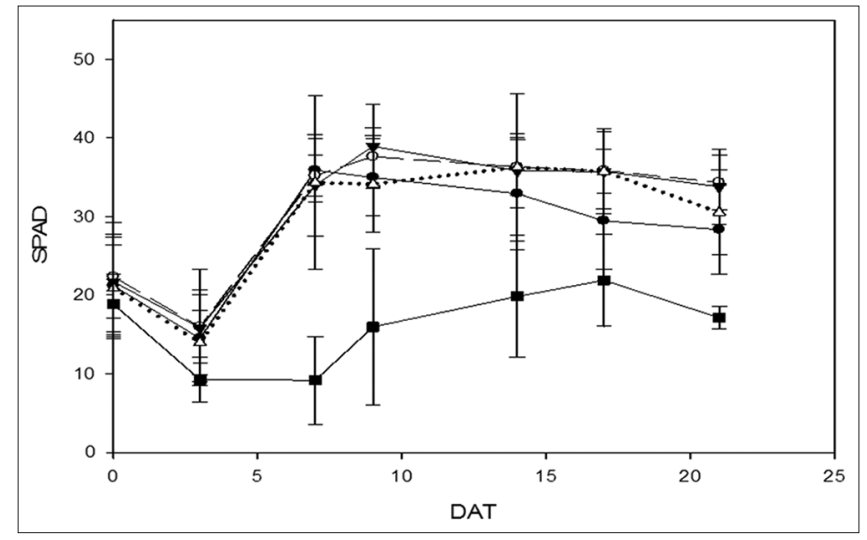

Fig 4. Effect of the different Fe chelate treatments on the SPAD index ( \pm standard deviation; $n=5$ ), measured in the first leaf level, of cucumber plants in hydroponic experiments: (•) Azotochelin ; (०) DPH; ( $)$ ) o,o-EDDHA; ( $\Delta$ ) EDTA; ( a ) Control. of the plants treated with EDTA/ $\mathrm{Fe}^{3+}$ was slightly higher than the plants treated with azotochelin/ $\mathrm{Fe}^{3+}$ and $\mathrm{DPH} /$ $\mathrm{Fe}^{3+}$. It must be noted that the leaves in the fifth level were small and were present only in few plants in each treatment.

In both samplings (7 and 21 DAT), the leaf dry weight (Table 2) of all treated plants was always greater than the control (HBED/ $\left.\mathrm{Fe}^{3+}, 2 \mu \mathrm{M}\right)$ and followed the same trend as the SPAD index. In the case of the roots and stem dry weight (Table 2), the differences between the control and the treated plants were significant only at the end of the experiment (21 days). Only the stem dry weight of the plants treated with azotochelin $/ \mathrm{Fe}^{3+}$ showed a slightly higher value at DAT 7. Among the treated plants at DAT 21 , the dry weight of the leaves and stems of the plants treated with azotochelin $/ \mathrm{Fe}^{3+}$ and $\mathrm{DPH} / \mathrm{Fe}^{3+}$ was lower than EDTA $/ \mathrm{Fe}^{3+}$ treatments but statistically comparable with the EDDHA/ $\mathrm{Fe}^{3+}$ treatment.

The iron concentration in leaves ( $\left.\mu \mathrm{mol} \mathrm{g}{ }^{-1} \mathrm{DW}\right)$, the total content of iron in leaves ( $\mu$ mol plant ${ }^{-1}$ ) (Table 3), and the concentrations of $\mathrm{Mn}$ and $\mathrm{Cu}$ in leaves (Table 4) were determined to evaluate the mineral status of the plants. In the first sampling (7 DAT), the Fe concentration $\left(\mu \mathrm{mol} \mathrm{g}{ }^{-1}\right.$ DW) and the total content of iron $\left(\mu \mathrm{mol}\right.$ plant $\left.^{-1}\right)$ in leaves was similar in all plants treated with the iron chelates and higher than in the control (HBED, $2 \mu \mathrm{M})$. At DAT 21, the total iron content $\left(\mu \mathrm{mol}\right.$ plant $\left.^{-1}\right)$ in the leaves of the treated plants was also higher than in the control plants. Plants treated with EDDHA/ $\mathrm{Fe}^{3+}$ showed the highest value. On the other hand, at DAT 21, the concentration of iron $(\mu \mathrm{mol}$ $\left.\mathrm{g}^{-1} \mathrm{DW}\right)$ measured in the leaves of the plants treated with EDTA $/ \mathrm{Fe}^{3+}$ was similar to the control plants. However, the SPAD value (Fig. 4) and the visual observation of the plants (Fig. 5) clearly evidenced the recovery from the chlorosis symptoms of the plants treated EDTA/ $\mathrm{Fe}^{3+}$ chelates, contrarily to the control plants.

The application of the iron chelates affected the uptake of other nutrients, which is evidenced by the high concentration of $\mathrm{Mn}$ and $\mathrm{Cu}$ (Table 4) measured in the

Table 1: Effect of the different Fe -chelate treatments on the SPAD index ( \pm standard deviation) in the most recently developed leaves of cucumber plants formed in different leaf levels after the application of the Fe-chelates treatments in hydroponic experiments.

\begin{tabular}{|c|c|c|c|c|c|c|c|}
\hline \multirow[t]{3}{*}{ Treatment } & \multicolumn{7}{|c|}{ DAT } \\
\hline & \multirow{2}{*}{$\begin{array}{c}3 \\
\text { Level } 2\end{array}$} & \multirow{2}{*}{$\begin{array}{c}7 \\
\text { Level } 3\end{array}$} & \multirow{2}{*}{$\begin{array}{c}14 \\
\text { Level } 4\end{array}$} & \multicolumn{4}{|c|}{21} \\
\hline & & & & Level 2 & Level 3 & Level 4 & Level 5 \\
\hline Control & $-^{*}$ & $16 \pm 10^{b}$ & $-^{*}$ & $15 \pm 5^{b}$ & $15 \pm 5^{b}$ & $15 \pm 3^{c}$ & $19 \pm 8^{b}$ \\
\hline Azotochelin & $24 \pm 3^{a}$ & $37 \pm 2^{\mathrm{a}}$ & $39 \pm 4 n s$ & $31 \pm 2^{a}$ & $31 \pm 5^{a}$ & $30 \pm 2^{b}$ & $30 \pm 6^{a}$ \\
\hline $\mathrm{DPH}$ & $21 \pm 4^{a}$ & $37 \pm 4^{a}$ & $-^{*}$ & $33 \pm 3^{a}$ & $29 \pm 3^{a}$ & $32 \pm 3^{b}$ & $28 \pm 3^{a}$ \\
\hline EDDHA & $19 \pm 4^{a b}$ & $37 \pm 3^{a}$ & $40 \pm 5$ & $35 \pm 4^{a}$ & $34 \pm 5 a$ & $33 \pm 5^{\mathrm{ab}}$ & $37 \pm 4^{a}$ \\
\hline EDTA & $12 \pm 7^{b}$ & $39 \pm 1^{a}$ & $39 \pm 2$ & $32 \pm 2^{a}$ & $31 \pm 5^{a}$ & $36 \pm 2^{a}$ & $34 \pm 2^{a}$ \\
\hline
\end{tabular}

Different letters in the same column denotes significant differences among treatments for Duncan test $(p<0.05)$. ns: no significant differences, ${ }^{*}$ Not complete leaf development at this level and time 
Table 2: Effect of the different Fe chelate treatments on the dry weight ( $\mathbf{g} ; \pm$ standard deviation) of leaf, root and stem in cucumber plants in hydroponic experiments

\begin{tabular}{|c|c|c|c|c|c|c|}
\hline \multirow[t]{3}{*}{ Treatment } & \multicolumn{6}{|c|}{ Dry weight } \\
\hline & \multicolumn{2}{|c|}{ leaves } & \multicolumn{2}{|c|}{ roots } & \multicolumn{2}{|c|}{ stems } \\
\hline & 7 DAT & 21 DAT & 7 DAT & 21 DAT & 7 DAT & 21 DAT \\
\hline Control & $0.18 \pm 0.05^{b}$ & $0.53 \pm 0.03^{c}$ & $0.06 \pm 0.02^{\text {ns }}$ & $0.08 \pm 0.01^{b}$ & $0.04 \pm 0.01^{b}$ & $0.08 \pm 0.01^{c}$ \\
\hline Azotochelin & $0.33 \pm 0.07^{a}$ & $1.41 \pm 0.22^{b}$ & $0.06 \pm 0.02$ & $0.31 \pm 0.05^{a}$ & $0.06 \pm 0.01^{a}$ & $0.36 \pm 0.08^{b}$ \\
\hline DPH & $0.29 \pm 0.10^{a}$ & $1.41 \pm 0.28^{b}$ & $0.06 \pm 0.02$ & $0.29 \pm 0.09^{a}$ & $0.05 \pm 0.01^{\mathrm{ab}}$ & $0.33 \pm 0.04^{b}$ \\
\hline EDDHA & $0.29 \pm 0.09^{a}$ & $1.69 \pm 0.44^{\mathrm{ab}}$ & $0.06 \pm 0.02$ & $0.31 \pm 0.09^{a}$ & $0.05 \pm 0.01^{b}$ & $0.41 \pm 0.08^{\mathrm{ab}}$ \\
\hline EDTA & $0.28 \pm 0.06^{a}$ & $1.95 \pm 0.33^{\mathrm{a}}$ & $0.06 \pm 0.02$ & $0.31 \pm 0.10^{\mathrm{a}}$ & $0.05 \pm 0.01^{\mathrm{ab}}$ & $0.45 \pm 0.09^{a}$ \\
\hline
\end{tabular}

Different letters in the same column denotes significant differences among treatments for Duncan test $(p<0.05)$. NS: No significant differences

Table 3: Effect of the different Fe chelate treatments on the leaf Fe concentration ( $\mu \mathrm{mol} \mathbf{~ g}^{-1} \mathrm{DW} ; \pm$ standard deviation) and Fe content ( $\mu \mathrm{mol}_{\text {plant }}{ }^{-1} ; \pm$ standard deviation) in cucumber plants grown in hydroponic experiments

\begin{tabular}{|c|c|c|c|c|}
\hline \multirow[t]{2}{*}{ Treatment } & \multicolumn{2}{|c|}{ Fe concentration in leaves $\left(\mu \mathrm{mol} \mathrm{g}^{-1} \mathrm{DW}\right)$} & \multicolumn{2}{|c|}{ Fe content in leaves $\left(\mu \mathrm{mol}\right.$ plant $\left.{ }^{-1} \mathrm{DW}\right)$} \\
\hline & 7 DAT & 21 DAT & 7 DAT & 21 DAT \\
\hline Control & $0.47 \pm 0.12^{b}$ & $0.97 \pm 0.17^{b}$ & $0.17 \pm 0.02^{b}$ & $0.51 \pm 0.06^{c}$ \\
\hline Azotochelin & $0.80 \pm 0.04^{a}$ & $1.15 \pm 0.11^{\mathrm{a}}$ & $0.52 \pm 0.10^{\mathrm{a}}$ & $1.62 \pm 0.24^{b}$ \\
\hline DPH & $0.86 \pm 0.09^{a}$ & $1.17 \pm 0.08^{\mathrm{a}}$ & $0.45 \pm 0.10^{\mathrm{a}}$ & $1.66 \pm 0.39^{b}$ \\
\hline EDDHA & $0.83 \pm 0.13^{\mathrm{a}}$ & $1.27 \pm 0.16^{\mathrm{a}}$ & $0.50 \pm 0.13^{a}$ & $2.11 \pm 0.44^{\mathrm{a}}$ \\
\hline EDTA & $0.80 \pm 0.12^{\mathrm{a}}$ & $0.94 \pm 0.11^{b}$ & $0.45 \pm 0.05^{a}$ & $1.79 \pm 0.10^{\mathrm{ab}}$ \\
\hline
\end{tabular}

Different letters in the same column denotes significant differences among treatments for Duncan test $(p<0.05)$. Ns: No significant differences

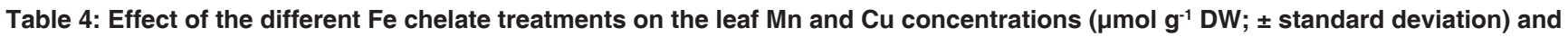
$\mathrm{Fe} / \mathrm{Mn}$ ratio in cucumber plants grown in hydroponic experiments

\begin{tabular}{|c|c|c|c|c|c|c|}
\hline \multirow[t]{3}{*}{ Treatment } & \multicolumn{4}{|c|}{$\begin{array}{l}\text { Concentration in leaves } \\
\left(\mu \mathrm{mol} \mathrm{g} \mathrm{g}^{-1} \mathrm{DW}\right)\end{array}$} & \multirow{2}{*}{\multicolumn{2}{|c|}{$\mathrm{Fe} / \mathrm{Mn}$}} \\
\hline & \multicolumn{2}{|c|}{ Mn } & \multicolumn{2}{|c|}{$\mathrm{Cu}$} & & \\
\hline & 7 DAT & 21 DAT & 7 DAT & 21 DAT & 7 DAT & 21 DAT \\
\hline Control & $3.3 \pm 0.4^{a}$ & $4.4 \pm 0.5^{\mathrm{a}}$ & $0.25 \pm 0.02^{\mathrm{a}}$ & $0.30 \pm 0.02^{a}$ & $0.15 \pm 0.04^{c}$ & $0.22 \pm 0.04^{d}$ \\
\hline Azotochelin & $2.5 \pm 0.3^{b}$ & $3.1 \pm 0.2^{b}$ & $0.19 \pm 0.01^{c}$ & $0.19 \pm 0.01^{c}$ & $0.33 \pm 0.03^{\mathrm{ab}}$ & $0.37 \pm 0.03^{\mathrm{bc}}$ \\
\hline DPH & $2.6 \pm 0.6^{b}$ & $2.8 \pm 0.5^{b}$ & $0.25 \pm 0.03^{a}$ & $0.22 \pm 0.03^{b}$ & $0.33 \pm 0.03^{\mathrm{ab}}$ & $0.43 \pm 0.03^{b}$ \\
\hline EDDHA & $2.3 \pm 0.4^{b}$ & $1.9 \pm 0.1^{c}$ & $0.18 \pm 0.01^{c}$ & $0.18 \pm 0.03^{c}$ & $0.35 \pm 0.03^{a}$ & $0.64 \pm 0.03^{a}$ \\
\hline EDTA & $3.2 \pm 0.2^{a}$ & $2.9 \pm 0.3^{b}$ & $0.21 \pm 0.02^{b}$ & $0.21 \pm 0.01^{b}$ & $0.25 \pm 0.03^{b}$ & $0.32 \pm 0.03^{c}$ \\
\hline
\end{tabular}

Different letters in the same column denotes significant differences among treatments for Duncan test $(p<0.05)$. ns: no significant differences

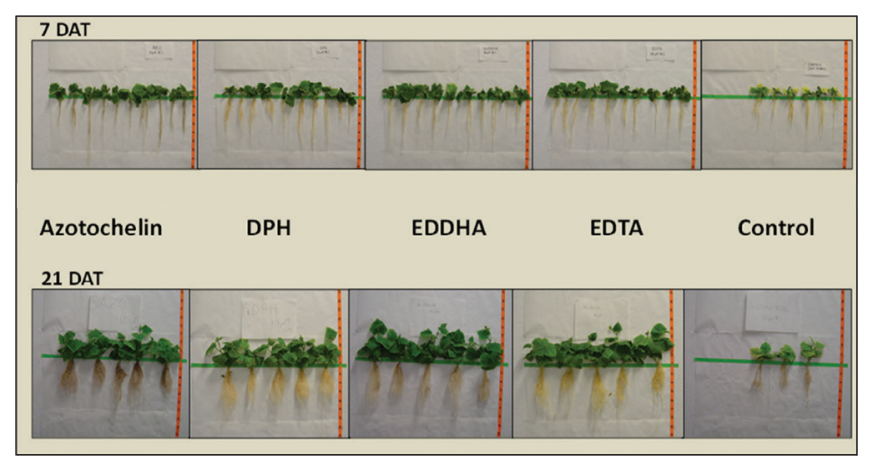

Fig 5. Cucumber plants after 7 and 21 days of treatment, in hydroponic culture, with the iron chelates $(10 \mu \mathrm{M} \mathrm{Fe})$ of Azotochelin, DPH, o,oEDDHA, EDTA and control plants $(2 \mu \mathrm{M} F e)$.

leaves of the untreated plants, especially at DAT 21. At DAT 7, the concentration of $\mathrm{Mn}$ in plants treated with EDTA $/ \mathrm{Fe}^{3+}$ and the concentration of $\mathrm{Cu}$ in plants treated with $\mathrm{DPH} / \mathrm{Fe}^{3+}$ were similar to the control plants.

The Fe/Mn ratio (Table 4) has been considered as an index of adequate iron nutrition for several crops mainly those grown in hydroponic conditions (Garcia-Marco et al., 2006). An increase of the $\mathrm{Fe} / \mathrm{Mn}$ ratio implies a recovery from iron chlorosis. At DAT 7, the Fe/Mn ratio in all the treated plants was higher than in the control. At DAT 21, the plants treated with EDTA/ $\mathrm{Fe}^{3+}$ showed the lowest $\mathrm{Fe} / \mathrm{Mn}$ ratio but higher than the control; on the other hand, the highest value was observed in plants treated with o,o-EDDHA/ $\mathrm{Fe}^{3+}$. The $\mathrm{Fe} / \mathrm{Mn}$ ratio obtained for $\mathrm{DPH} / \mathrm{Fe}^{3+}$ and azotochelin $/ \mathrm{Fe}^{3+}$ treatments were similar to EDDHA/ $\mathrm{Fe}^{3+}$, at day 7 , but lower at day 21 .

\section{DISCUSSION}

Plants treated with DPH/ $/ \mathrm{Fe}^{3+}$ or azotochelin $/ \mathrm{Fe}^{3+}$ chelates showed similar SPAD values (Table 1), leaf dry weight (Table 2) and iron concentration in leaves $\left(\mu \mathrm{mol} \mathrm{g}^{-1} \mathrm{DW}\right.$ ) (Table 3) as those treated with o,o-EDDHA $/ \mathrm{Fe}^{3+}$ chelate; these results suggest the same level of recovery from the iron chlorosis symptoms.

At the end of the experiment (DAT 21), the plants treated with EDTA/ $/ \mathrm{Fe}^{3+}$ chelates showed lower values of iron 
concentration ( $\left.\mu \mathrm{mol} \mathrm{g} \mathrm{g}^{-1} \mathrm{DW}\right)$ and iron content $(\mu \mathrm{mol}$ plant $^{-1} \mathrm{DW}$ ) in leaves than those treated with EDDHA/ $\mathrm{Fe}^{3+}$ chelate; these differences are in good agreement with published results (Nadal et al., 2012). However, at DAT 21, no significant differences were observed in leaf iron concentration $\left(\mu \mathrm{mol} \mathrm{g}{ }^{-1} \mathrm{DW}\right)$ measured in control plants and in plants treated with EDTA/ $\mathrm{Fe}^{3+}$ (Table 3). These results are not in agreement with the leaf SPAD (Table 1; 21 DAT, levels 4 and 5) and dry biomass (Table 2; 21 DAT) results nor with the visible recovery from the chlorosis symptoms (Fig. 5) showed by plants treated with EDTA/ $\mathrm{Fe}^{3+}$.

No differences were observed in the leaf dry weight of plants treated with all iron chelates at DAT 7. However, at DAT 21, the plants treated with EDTA showed a similar SPAD value (or higher at level 4) (Table 1) and a lower Fe concentration (Table 3), but a higher leaf dry biomass (Table 2) values when compared with the siderophores treatments, which suggests a possible dilution effect.

A good correlation between the SPAD values (Table 1) and the amount of iron in leaves was obtained when the total iron content in leaves $\left(\mu \mathrm{mol}\right.$ plant $\left.{ }^{-1} \mathrm{DW}\right)$ was determined. Therefore, this parameter seems to be more adequate than the leaf iron concentration ( $\mu \mathrm{mol} \mathrm{g}^{-1} \mathrm{DW}$ ) for comparing the iron uptake from different treatments: $\mathrm{DPH} / \mathrm{Fe}^{3+}$, azotochelin $/ \mathrm{Fe}^{3+}$, EDTA $/ \mathrm{Fe}^{3+}$ and o,o-EDDHA $/ \mathrm{Fe}^{3+}$.

At DAT 7, all plants treated with the iron chelates showed similar leaf iron content; these results suggest that $\mathrm{DPH} / \mathrm{Fe}^{3+}$ and azotochelin/ $\mathrm{Fe}^{3+}$ are as efficient as EDTA/ $\mathrm{Fe}^{3+}$ and o,o-EDDHA/ $\mathrm{Fe}^{3+}$ for the treatment of plants showing symptoms of iron chlorosis. However, after the initial recovery from the symptoms, o,o-EDDHA/ $\mathrm{Fe}^{3+}$ was more efficient in supplying iron to plants; at DAT 21, plants treated with o,o-EDDHA/ $\mathrm{Fe}^{3+}$ showed the highest iron content in leaves.

The effectiveness of the Fe chelates, as Fe sources to plants, depends, not only of the formation constant of the Fe chelate, and thus on the ability to maintain Fe in solution, but also of the equilibrium constants of the reactions between the ligand with the competing cations (Alcaniz et.al. 2017; Alvarez-Fernandez et.al. 1997). An important characteristic of siderophores is the high selectivity for iron (Hider and Kong, 2010) that ensures the stability of the iron chelates in the presence of other metal ions. In the case of EDTA, the chelated iron can be displaced by other cations in solution that form stable complexes with EDTA and thus reduces the soluble Fe in solution available for the plants (Villen et al., 2007). However, the same behaviour is not expected to occur in the case of DPH and o,o-EDDHA under hydroponic conditions up to $\mathrm{pH} 9$ (Martins et.al. 2017).
Besides the stability of the iron chelate, its behavior when it is used as a substrate of the enzyme FCR is also considered an important step in the evaluation of the efficiency of a chelating agent to provide iron to plants. The relationship between the efficiency of a chelate to deliver iron to plants and the reduction of iron(III) chelated by the reductase is not yet clear and is still in discussion (Lucena et al., 2008; Escudero et al. 2012). Several authors have demonstrated that the amount of iron(III) reduced by the plants gives only partial information about the uptake process (Lucena and Chaney, 2006; Nadal et al., 2012). In fact, higher reduction rate observed with EDTA/ $\mathrm{Fe}^{3+}$ chelate did not lead to higher amount of iron in the leaves (Table 3). This fact may be due to the high stability of the EDTA $/ \mathrm{Fe}^{2+}$ chelate that serves as an $\mathrm{Fe}^{2+}$ trapping agent and prevents most of the iron uptake by the plants and/ or due to the possible dilution effect, already discussed above (Lucena and Chaney, 2006; Nadal et al., 2012). On the contrary, siderophores possess a higher affinity for iron(III) than iron(II) (Villen et al., 2007; Hider and Kong, 2010). Therefore, it was expected that $\mathrm{DPH} / \mathrm{Fe}^{3+}$ and especially azotochelin/ $/ \mathrm{Fe}^{3+}$ were more efficient than EDTA $/ \mathrm{Fe}^{3+}$ in supplying iron to plants, which was not observed (Table 3). The low redox potential, common in microbial siderophores, probably limited the $\mathrm{Fe}$ acquisition from $\mathrm{DPH} / \mathrm{Fe}^{3+}$ and azotochelin $/ \mathrm{Fe}^{3+}$ chelates.

In fact, in the reductase assays, the reduction rate obtained for Fe(III)-DPH was significantly lower than for Fe(III)EDTA. Furthermore, the redox potentials determined for rhodotorulic acid (-0.419 V vs NHE) (Crumbliss and Harrington, 2009) and for several dihydroxamic acids compounds at high-pH conditions $(-0.261$ to $-0.446 \mathrm{~V} v \mathrm{~s}$ NHE) (Crumbliss and Harrington, 2009) suggest that the redox potential of Fe(III)-DPH chelate should be much lower than the redox potential of Fe(III)-EDTA chelate (+0.120 V, vs NHE) (Gomez-Gallego et al., 2005).

Catechol-based siderophores, such as azotochelin, are effective iron chelators, but the low redox potential of these compounds can prevent the reduction by most biological reductases (Hider and Kong, 2010). However, even though, the results of FCR experiments for $\mathrm{Fe}(\mathrm{III})$-azotochelin were inconclusive, Fe(III)azotochelin was able to deliver iron to plants (Table 3).

The reduction and iron release from cathecholamides siderophores, observed in several microorganisms, involves the shift of the coordination binding mode from the cathecolate to the salicylate mode after the protonation of the distal hydroxyl donor at each cathecolamide donor group (Abergel et al., 2006; Harrington et al., 2012).

In plants, it is possible that this binding mode shift occurs near the roots because it is known that a deficiency of 
iron increases the production and concentration of organic acids that acidifies the rhizosphere (Marschner and Romheld, 1994). Additionally, dicots mainly use Strategy I for iron uptake; this strategy involves the reduction of iron (III) chelate by reductase before the transport across the plasma but it also generates a proton gradient to facilitate iron(III) solubilization outside the cell (Bellenger et al., 2007). Despite the use of $0,1 \mathrm{mM}$ HEPES, as a $\mathrm{pH}$ buffer, the increased activity of $\mathrm{H}^{+}$-ATPase in roots during iron deprivation acidifies the rhizosphere by excreting $\mathrm{H}^{+}$and may decrease the $\mathrm{pH}$ of the rizhosphere by $0.5-1 \mathrm{pH}$ units. This is consistent with the fact that the FCR activity decreases with increasing $\mathrm{pH}$ (Lucena and Chaney, 2007).

The shift from the cathecolate to the salicylate mode not only lowers the affinity for binding trivalent metal cations but also shifts the redox potentials of iron(III) complexes into the range where iron(III) can be reduced by biological reductants (Bellenger et al., 2007; Harrington et al., 2012). Thus, the decrease of the absorbance at both 535 and $630 \mathrm{~nm}$ in the reductase assay with azotochelin (data not shown) may be due to the reduction of iron(III) to iron(II), after the shift to the salicylate coordination mode, with the formation of colorless Fe(II)-catechol complexes (Hider et al., 1981). The increase of the absorbance at $535 \mathrm{~nm}$ (data not shown), after the first 20 minutes, suggests the release of iron(II) from azotochelin by competition with BDPS. Therefore, as in the case of EDTA $/ \mathrm{Fe}^{3+}$ chelate, the affinity for iron(II), showed by azotochelin, lowers the release efficiency of $\mathrm{Fe}^{2+}$ and may also affect the supply of iron to plants (Miethke 2013).

The redox potential of o,o-EDDHA/ $/ \mathrm{Fe}^{3+}$ chelate $(-0.560$ $\mathrm{V}$, vs NHE) (Gomez-Gallego et al., 2005) is also very low, probably lower than the redox potential of $\mathrm{DPH} / \mathrm{Fe}^{3+}$, assuming the values described in the literature for several dihyroxamate compounds. From this and considering the lower stability of the $\mathrm{DPH} / \mathrm{Fe}^{3+}$ chelate compared with o,o-EDDHA $/ \mathrm{Fe}^{3+}$ chelate, it was expected that the $\mathrm{DPH} / \mathrm{Fe}^{3+}$ chelate would be a better substrate for FCR than $\mathrm{o}, \mathrm{o}-\mathrm{EDDHA} / \mathrm{Fe}^{3+}$ chelate. However, as in the case of azotochelin, a mechanism, involving changes in the coordination of the o,o-EDDHA $/ \mathrm{Fe}^{3+}$ chelate at a more acidic $\mathrm{pH}$ in the vicinity of the roots, has been already proposed (Gomez-Gallego et al., 2005). This fact can probably explain the effective reduction of o,o-EDDHA/ $\mathrm{Fe}^{3+}$ chelate (Fig. 3) and the iron uptake from o,o-EDDHA/ $\mathrm{Fe}^{3+}$ chelate by plants despite the low redox potential of the very stable iron(III) chelate formed with o,o-EDDHA.

Significant differences between the treatments were observed only at DAT 21 when higher content of iron was measured in leaves of plants treated with o,o-EDDHA (Table 3). These results may suggest that, not only the reduction mechanism, but also the iron transport within the plant may depend on the chelate used. In fact, we cannot exclude the direct uptake of $\mathrm{Fe}(\mathrm{III})-\mathrm{DPH}$ or $\mathrm{Fe}(\mathrm{III})$-azotochelin complexes by the plants. This strategy should involve the incorporation of the bacterial siderophore, by analogy to the iron uptake Strategy II, through their incorporation in roots when chelated with iron, as it was already proposed by other authors (Chen et.al. 2000; Vansuyt et.al. 2007).

In the various treatments, the uptake of $\mathrm{Cu}$ and $\mathrm{Mn}$ by plants was affected by the uptake of iron. The leaf concentrations of $\mathrm{Cu}$ and $\mathrm{Mn}$ (Table 4) evidenced the favored uptake of those cations under iron deficiency conditions. The higher concentration of $\mathrm{Cu}$ and $\mathrm{Mn}$ in the leaves of the untreated plants (Control, $2 \mu \mathrm{M} \mathrm{Fe}$ ), that was evident at the end of the experiment, is related with the involvement of the Iron Regulated Trasporter 1 (IRT1), not only in the uptake of iron, but also in the absorption of those cations, by the roots (Rodriguez-Lucena et al., 2010b; Maqueda et al., 2011). Moreover, the high affinity of o,oEDDHA for $\mathrm{Cu}$ normally reduces the $\mathrm{Cu}$ concentration in leaves when o,o-EDDHA/ $\mathrm{Fe}^{3+}$ is used in hydroponics conditions (Yunta et al., 2003c).

The Fe/Mn ratio obtained with the treatments of DPH/ $\mathrm{Fe}^{3+}$ and azotochelin $/ \mathrm{Fe}^{3+}$ chelates were similar in both samplings (7 and $21 \mathrm{DAT}$ ) and much higher than those obtained in the untreated plants. These results indicate a good recovery from iron chlorosis. However, these results were lower than the ones obtained in the second sampling (21 DAT) of the treatment with o,o-EDDHA $/ \mathrm{Fe}^{3+}$.

The results obtained in this work evidence that the iron chelates of the siderophore azotochelin and the siderophore mimic DPH are able to supply iron to plants, in hydroponics solution at $\mathrm{pH} 7.5$, to correct iron chlorosis and to maintain a good nutritional status of the plants. Both iron chelates were as efficient as Fe(III)-EDTA and Fe(III)EDDHA chelates in treating plants with visible symptoms of iron chlorosis, in hydroponic culture, at $\mathrm{pH}$ 7.5.

EDTA and o,o-EDDHA are the most widely used synthetic chelates for correcting iron chlorosis but they are not biodegradable. The catecholate and the hydroxamate groups, present in the azotochelin and in DPH compounds, respectively, are the most common in microbial siderophores and although DPH is not produced naturally, it is well known the existence of hydroxamate degrading microorganisms (Hördt et al., 2000). Thus, taking into account the nature of these compounds, the results obtained in this work open the possibility of application of the iron(III) chelates of azotochelin and DPH for more environmental friendly iron fertilization of plants grown in calcareous soils, which is presently under study. 


\section{ACKNOWLEDGMENTS}

This work received financial support from the European Union (FEDER funds through COMPETE) through Project (PTDC-AAC-AMB-111206-2009). J. G. Martins acknowledges a Ph.D grant fellowship (SFRH/ BD/64718/2009) financed by FCT.

\section{REFERENCES}

Abergel, R. J., J. A. Warner, D. K. Shuh and K. N. Raymond. 2006. Enterobactin protonation and iron release: Structural characterization of the salicylate coordination shift in ferric enterobactin. J. Am. Chem. Soc. 128: 8920-8931.

Alcaniz, S., J. D. Jorda and M. Cerdan. 2017. Effectiveness of iorn ethylenediamine-N,N'-bis(hydroxyphenylacetic) acid (o,oEDDHA/Fe3+) formulations with differetn ratios of meso and d,I-racemic isomers as iron fertilizers. J. Agric. Food Nutr. 65: 253-259.

Alvarez-Fernandez, A., A. Garate and J. J. Lucena. 1997. Interaction of iron chelates with several soil materials and with a soil standard. J. Plant Nutr. 20: 559-572.

Barclay, S. J., B. H. Huynh and K. N. Raymond. 1984. Coordination chemistry of microbial iron transport compounds .27. Dimeric iron (III) complexes of dihydroxamate analogs of rhodotorulic acid. Inorg. Chem. 23: 2011-2018.

Bellenger, J. P., F. Arnaud-Neu, Z. Asfari, S. C. B. Myneni, E. I. Stiefel and A. M. L. Kraepiel. 2007. Complexation of oxoanions and cationic metals by the biscatecholate siderophore azotochelin. J. Biol. Inorg. Chem. 12: 367-376.

Chen, L., W. A. Dick, and J. G. Streeter. 2000. Production of aerobactin by microorganisms from a compost enrichment culture and soybean utilization. J. Plant Nutr. 23: 2047-60.

Cornish, A. S and W. J. Page. 1998. The catecholate siderophores of Azotobacter vinelandii: Their affinity for iron and role in oxygen stress management. Microbiology. 144: 1747-1754.

Crumbliss, A. L and J. M. Harrington. 2009. Iron sequestration by small molecules: Thermodinamic and kinetic studies of natural siderophores and synthetic model compounds. In: Van Eldik, R., C. D. Hubbard, (Eds.), Advances in Inorganic Chemistry. Vol. 61. Elsevier Academic Press Inc., San Diego, pp. 179-250.

Ding, H., L. Duan, J. Li, H. Yan, M. Zhao, F. Zhang and W. X. Li. 2010. Cloning and functional analysis of the peanut iron transporter AhIRT1 during iron deficiency stress and intercropping with maize. J Plant Physiol. 167(12): 996-1002.

Ding, H., L. Duan, H. Wu, R. Yang, H. Ling, W. X. Li and F. Zhang. 2009. Regulation of AhFRO1, an Fe (III)-chelate reductase of peanut, during iron deficiency stress and intercropping with maize. Physiol. Plant. 136(3): 274-283.

Duhme, A. K., R. C. Hider and H. H. Khodr. 1996. Spectrophotometric competition study between molybdate and $\mathrm{Fe}(\mathrm{III})$ hydroxide on $\mathrm{N}, \mathrm{N}$-bis(2,3-dihydroxybenzoyl)-L-lysine, a naturally occurring siderophore synthesized by Azotobacter vinelandii. Biometals. 9: 245-248.

Duhme, A. K., R. C. Hider and H. H. Khodr. 1997. Synthesis and iron-binding properties of protochelin, the tris(catecholamide) siderophore of Azotobacter vinelandii. Chem. Bericht. Recueil. 130: 969-973.

Escudero, R., M. Gomez-Gallego, S. Romano, I. Fernandez, A. Gutierrez-Alonso, M. A. Sierra, S. Lopez-Rayo, P. Nadal and J.
J. Lucena. 2012. Biological activity of Fe(III) aquo-complexes towards ferric chelate reductase (FCR). Org. Biomol. Chem. 10: 2272-2281.

Ferreira, C. M. H., I. S. S. Pinto, E. V. Soares and H. M. V. M. Soares. 2015. (Un) suitability of the use of $\mathrm{pH}$ buffers in biological, biochemical and environmental studies and its interaction with metal ions-a review. RSC Adv. 5: 30989-31003.

Garcia-Marco, S., N. Martinez, F. Yunta, L. Hernandez-Apaolaza and J. J. Lucena. 2006. Effectiveness of ethylenediamine-N(ohydroxyphenylacetic)- $\mathrm{N}$ '(p-hydroxy-phenylacetic) acid (o,pEDDHA) to supply iron to plants. Plant Soil. 279: 31-40.

Gomez-Gallego, M., D. Pellico, P. Ramirez-Lopez, M. J. Mancheno, S. Romano, M. C. de la Torre and M. A. Sierra. 2005. Understanding of the mode of action of Fe-III-EDDHA as iron chlorosis corrector based on its photochemical and redox behavior. Chem. Eur. J. 11: 5997-6005.

Harrington, J. M., J. R. Bargar, A. A. Jarzecki, J. G. Roberts, L. A. Sombers and O. W. Duckworth. 2012. Trace metal complexation by the triscatecholate siderophore protochelin: Structure and stability. Biometals. 25: 393-412.

Hider, R. C and X. Kong. 2010. Chemistry and biology of siderophores. Nat. Prod. Rep. 27: 637-657.

Hider, R. C., A. R. Mohdnor, J. Silver, I. E. G. Morrison and L. V. C. Rees. 1981. Model compounds for microbial iron-transport compounds .1. Solution chemistry and Mossbauer study of iron (II) and iron (III) complexes from phenolic and catecholic systems. J. Chem. Soc. Dalton Trans. 2: 609-622.

Hördt, W., V. Romheld and G. Winkelmann. 2000. Fusarinines and dimerum acid, mono-and dihydroxamate siderophores from Penicillium chrysogenum, improve iron utilization by strategy and strategy II plants. Biometals. 13: 37-46.

Jin, C. W., Y. Q. Ye, and S. J. Zheng. 2014. An underground tale: Contribution of microbial activity to plant iron acquisition via ecological processes. Ann Bot. 113: 7-18.

Leydier, A., D. Lecercle, S. Pellet-Rostaing, A. Favre-Reguillon, F Taran and M. Lemaire. 2008. Sequestering agent for uranyl chelation: A new family of CAMS ligands. Tetrahedron. 64: 66626669.

Lucena, J. J and R. L. Chaney. 2006. Synthetic iron chelates as substrates of root ferric chelate reductase in green stressed cucumber plants. J. Plant Nutr. 29: 423-439.

Lucena, J. J and R. L. Chaney. 2007. Response of cucumber plants to low doses of different synthetic iron chelates in hydroponics. J. Plant Nutr. 30: 795-809.

Lucena, J. J., J. A. Sentis, M. Villen, T. Lao and M. Perez-Saez. 2008. IDHA chelates as a micronutrient source for green bean and tomato in fertigation and hydroponics. Agron. J. 100: 813-818.

Jian Feng, M. and L. Hong-Qing. 2009. Iron for plants and humans. Plant Soil. 325: 1-3.

Maqueda, C., J. F. Herencia, J. C. Ruiz and M. F. Hidalgo. 2011. Organic and inorganic fertilization effects on DTPA-extractable $\mathrm{Fe}, \mathrm{Cu}, \mathrm{Mn}$ and $\mathrm{Zn}$, and their concentration in the edible portion of crops. J. Agric. Sci. 149: 461-472.

Marschner, $H$ and V.Romheld. 1994. Strategies of plants for acquisition of iron. Plant Soil. 165: 261-274.

Martell, A. E., R. M. Smith. 2004. NIST Standard Reference Database 46 Version 8.0, NIST Critically Selected Stability Constants Of Metal Complexes Database. US Department of Commerce, National Institute of Standards and Technology, Gaithersburg, MD.

Martins, J. G., C. M. H. Ferreira, S. D. Suvendu, M. T. Barros and H. M. V. M. Soares. 2017. N,N'-Dihydroxy-N,N'- 
diisopropylhexanediamide, a siderophore analogue, as a possible iron chelating agent for hydroponic conditions: Metal equilibrium studies. J. Iran. Chem. Soc. 14: 1079-1088.

Miethke, M. 2013. Molecular strategies of microbial iron assimilation: From high-affinity complexes to cofactor assembly systems. Metallomics. 5: 15-28.

Nadal, P., S. Garcia-Marco, R. Escudero and J. J. Lucena. 2012. Fertilizer properties of DCHA/Fe3+ Plant Soil. 356: 367-379.

Perrin, D. D., W. L. F. Armarego and D. R. Perrin. 1980. Purification of Laboratory Chemicals. Pergamon., New York.

Rodriguez-Lucena, P., A. Benedicto, J. J. Lucena, J. A. RodriguezCastrillon, M. Moldovan, J. I. G. Alonso and L. HernandezApaolaza. 2011. Use of the stable isotope Fe-57 to track the efficacy of the foliar application of lignosulfonate/Fe3+ complexes to correct Fe deficiencies in cucumber plants. J. Sci. Food Agric. 91: 395-404.

Rodriguez-Lucena, P., L. Hernandez-Apaolaza and J. J. Lucena. 2010a. Comparison of iron chelates and complexes supplied as foliar sprays and in nutrient solution to correct iron chlorosis of soybean. J. Plant Nutr. Soil Sci. 173: 120-126.

Rodriguez-Lucena, P., E. Ropero, L. Hernandez-Apaolaza and J. J. Lucena. 2010b. Iron supply to soybean plants through the foliar application of IDHA/Fe3+: Effect of plant nutritional status and adjuvants. J. Sci. Food Agric. 90: 2633-2640.

Schecher, W. D. and D. C. McAvoy. 2001. MINEQL+, A Chemical Equilibrium Modeling System Version 4.5 for Windows. Environmental Research Software., Hallowell, Maine.

Smith, W. L and K. N. Raymond. 1980. Synthesis of aliphatic dimeric $\mathrm{N}$-isopropylhydroxamic acids and the crystal and molecularstructure of $\mathrm{N}, \mathrm{N}$ '-dihydroxy -N,N'-diisopropylhexanediamide - hydroxamic acid in the trans conformation. J. Am. Chem. Soc. 102: 1252-1255.

Vansuyt, G., A. Robin, J.-F. Briat, C. Curie and P. Lemanceau. 2007. Iron acquisition from Fe-pyoverdine by Arabidopsis thaliana. Mol. Plant Microbe Interact. 20: 441-447.

Villen, M., A. Garcia-Arsuaga and J. J. Lucena. 2007. Potential use of biodegradable chelate N-(1,2-dicarboxyethyl)-D,L-aspartic acid/ Fe3+ as an Fe fertilizer. J. Agric. Food Chem. 55: 402-407.

Xiong, H., Y. Kakei, T. Kobayashi, X. Guo, M. Nakazono, H. Takahashi, H. Nakanishi, H. Shen, F. Zhang, N. K. Nishizawa and Y. Zuo 2013. Molecular evidence for phytosiderophore-induced improvement of iron nutrition of peanut intercropped with maize in calcareous soil. Plant Cell Environ. 36(10): 1888-1902.

Yunta, F., M. A. Sierra, M. Gomez-Gallego, R. Alcazar, S. GarciaMarco and J. J. Lucena. 2003a. Methodology to screen new iron chelates: Prediction of their behavior in nutrient solution and soil conditions. J. Plant Nutr. 26: 1955-1968.

Yunta, F., S. Garcia-Marco and J. J. Lucena. 2003b. Theoretical speciation of ethylenediamine-N-(o-hydroxyphenylacetic)-N '-(p-hydroxyphenylacetic) acid (o,p-EDDHA) in agronomic conditions. J. Agric. Food Chem. 51: 5391-5399.

Yunta, F., S. Garcia-Marco, J. J. Lucena, M. Gomez-Gallego, R. Alcazar and M. A. Sierra. 2003c. Chelating agents related to ethylenediamine bis(2-hydroxyphenyl)acetic acid (EDDHA): Synthesis, characterization, and equilibrium studies of the free ligands and their $\mathrm{Mg}^{2}+, \mathrm{Ca}^{2}+, \mathrm{Cu}^{2}+$, and $\mathrm{Fe}^{3}+$ chelates. Inorganic Chemistry. 42: 5412-5421.

Zhang, G., S. A. Amin, F. C. Kuepper, P. D. Holt, C. J. A. Carrano and A. Butler. 2009. Ferric stability constants of representative marine siderophores: Marinobactins, aquachelins, and petrobactin. Inorg. Chem. 48: 11466-11473. 